\title{
THE EFFECTS OF HAZE ON THE MEASURED SOIL REFLECTANCE AND DROUGHT MONITORING MODELS BASED ON SPECTRAL FEATURE SPACE
}

\author{
Haixia Feng ${ }^{1}$, Liming Wang $^{2 *}$, Lin $Z \mathrm{Ch}^{3}$, Shanshan Shao ${ }^{1}$, Xiangjun Meng ${ }^{1}$ \\ 1. Research center for road safety, emergency and disaster reduction technology, Shandong Jiaotong \\ University, Jinan 250023, China \\ 2. Key Laboratory of Digital Earth Science, Institute of Remote Sensing and Digital Earth, Chinese \\ Academy of Sciences, Beijing, 100094, China \\ 3. National Satellite Meteorological Centre, Beijing, 100094, China
}

\begin{abstract}
In China, the haze is breaking out, and it cannot be solved in a few decade years. In this paper, we used haze simulation laboratory, simulated the particulate concentration through the control experiment, and measured the soil reflectance under the different the particulate concentration. Then we analyzed the effect of different hazes on the different soil moisture reflectance: the reflectance is relatively larger when the concentration increases, But when the concentration of the particles increases to 150 $\mathrm{ug} / \mathrm{m} 3$, the curve becomes smooth. While the difference of the different soil moisture reflectance is decreasing. The different haze conditions (particulate matter concentration) makes the measured soil spectra curve change, so Some drought monitoring model based on spectral feature space(PDI, MPDI, SPSI, MSPSI) inevitably influence.
\end{abstract}

Index Terms - haze, simulation, soil reflectance, drought monitoring model

\section{INTRODUCTION}

With the rapid growth of China's economy, the haze is breaking out. The haze spread 25 provinces, more than 100 large and medium-sized cities in 2013. The area of heavy air pollution is more than 1.81 million square kilometers in 2014. Worst of all, the haze cannot be solved in a few years. At present, the basic condition for most of remote sensing drought monitoring model is clear weather. The haze has seriously impact on drought remote sensing monitoring. Some technology and methods about removing haze had been studied, but they cannot completely remove the effect of haze.

There are many studies about the causes, composition, influence, and detriment of haze. Characterization and source apportionment of particle number concentration at a semi-urban tropical environment is studied, which improved understanding of the haze episode particularly on PM2.5 by investigating the mass concentrations and its relation to chemical compositions and related gaseous-mteorological parameters during 2011 haze episode at UKM Bangi. (Md Firoz Khan,2015). Fine particulate matter which primarily derived from direct emission from combustion processes has most concern towards the health effect due to its toxicological and physiological considerations which suggest that the fine particles may play the largest role in affecting human health (Pope III and Dockery 2006). Indoor air concentrations of particulate matter (PM10 and PM2. 5) in German schools was studied $(\mathrm{H}$ Fromme, 2006). The characterization of major pollution events (dust, haze, and two festival

\footnotetext{
* Corresponding author: Liming Wang, Email: fhxlxt@126.com
} 
events) at Agra, India was analyzed (Tripti Pachauri, et al, 2013), and the characterization and source apportionment of particle number concentration at a semi-urban tropical environment were analyzed (Norhaniza Amil, et al, 2014). The United States Environmental Protection Agency promulgated the air quality standard for PM2.5 in 1997, the annual the average PM2.5 concentration limits for $15 \mathrm{ug} / \mathrm{m}^{3}$, daily average concentration limit value for 65 $\mathrm{ug} / \mathrm{m}^{3}$, and daily average concentration limits was improved to $35 \mathrm{ug} / \mathrm{m}^{3}$.

In this paper, we mainly discuss the effects of haze on the measured soil reflectance and drought monitoring model based on spectral feature space.

\section{MATERIALS AND METHODS Sampling Site Description}

Shandong Jiaotong University was chosen as the sampling point with geographical latitude of $36.67828^{\circ}$, and longitude of $116.95649^{\circ}$.

\section{Experimental method and procedure}

Simple haze Simulation Laboratory has established, but it is the need to improve. We build a simple plastic shed with movable roof at the top soil moisture control experimental field. Control the haze situation using a large wind machine blowing milled the different size particle. The concentrations of PM2.5 was respectively 35, 75, 150 micrograms per cubic meter, and corresponding Air Quality Index (AQI) were respectively 50, 100, 200. They were measured by LD-5 laser dust meter.

We measured the soil spectra curve under different water stress used spectrometer, and measure the soil spectra curve under different haze situation, then make comparisons.

The soil block is a circular with a radius of $10 \mathrm{~cm}$, and it's thickness is $5 \mathrm{~cm}$ is. It was baked for 24 hours, then the weight is measured by a balance and water was added. The percentage of soil moisture and water was respectively $0,5,10$, $15,20,30,40,50$.
The spectrometer is AvaField-1 made by Holland, and it's measurement range is $300-1100 \mathrm{~nm}$, Sampling interval is $0.6 \mathrm{~nm}$.

\section{RESULTS AND DISCUSSION}

The soil curves of different moisture content in different haze conditions are as follows:

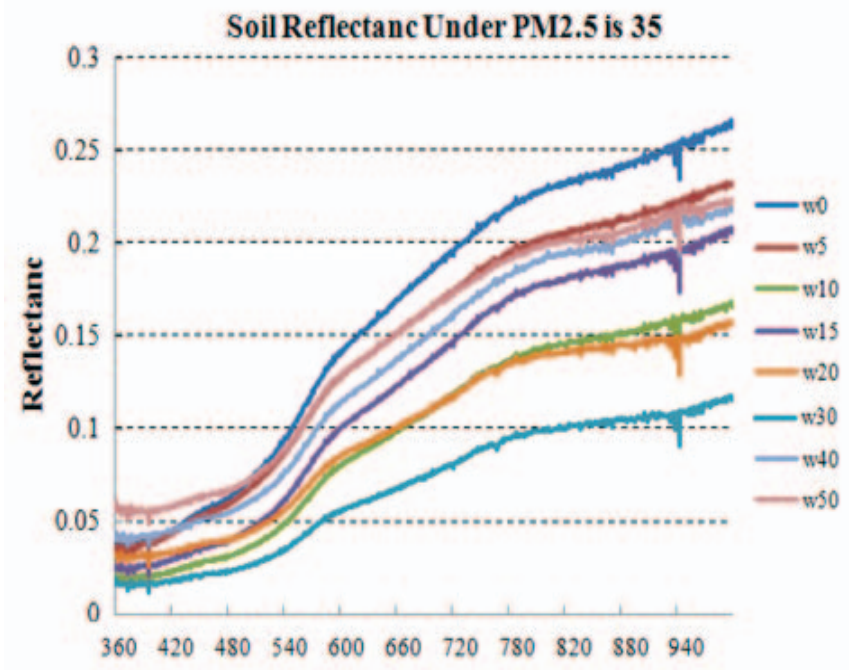

Fig.1 Soil Reflectanc Under PM2.5 is 35

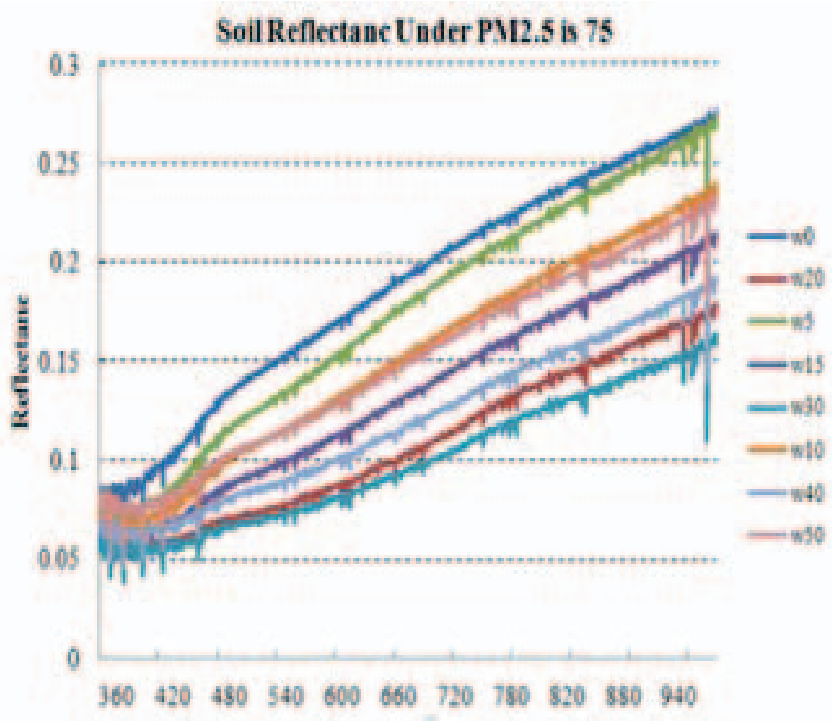

Fig.2 Soil Reflectanc Under PM2.5 is 75 


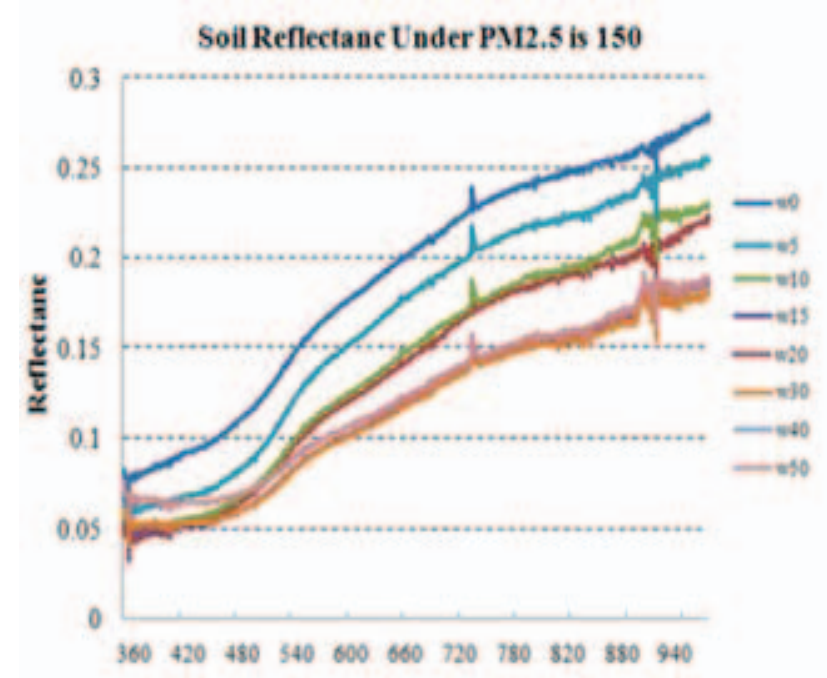

Fig.3 Soil Reflectanc Under PM2.5 is 150

They are illustrated in Fig.1 - Fig.3 that the spectral curve become ups and downs, no longer smooth, especially in the short range of 300 to $500 \mathrm{~nm}$, when the concentration of particulate from $35 \mathrm{ug} / \mathrm{m} 3$ to $75 \mathrm{ug} / \mathrm{m} 3$. But when the concentration of the particles increases to 150 $\mathrm{ug} / \mathrm{m} 3$, the curve becomes smooth. While the difference of the different soil moisture reflectance is decreasing.

The different haze conditions (particulate matter concentration) makes the measured soil spectra curve change, so Some drought monitoring model based on spectral feature space(PDI, MPDI, SPSI, MSPSI) inevitably influence:

(1) the fluctuation increase of soil reflectivity curve will inevitably make that the soil drought condition is not accurate calculated by model according to the spectral features.

(2) the reflectance decrease of the different moisture content is bound to make the soil drought abnormal.

\section{CONCLUSIONS}

In this paper, we mainly measured the soil reflectance in under the different the particulate concentration used haze simulation laboratory. Then analyzed the effect of different hazes on the different soil moisture reflectance and on drought monitoring model based on spectral feature space. The main conclusions were followed:

(1)the reflectance is relatively larger when the concentration increases;

(2)But the curve becomes smooth again, when the concentration of the particles increases to $150 \mathrm{ug} / \mathrm{m} 3$, While the difference of the different soil moisture reflectance is decreasing.

(3) the soil drought condition is not accurate for the fluctuation increase of soil reflectivity curve, which will inevitably cause the model calculated result not accurate according to the spectral features.

(4) the reflectance decrease of the different moisture content is bound to make the soil drought abnormal.

Acknowledgments: this work is supported by the National Natural Science Foundation of China $(41101312,41230747)$, the Fund of China Scholarship Council and the Study Abroad Fund of Shandong Jiaotong University.

\section{References}

[1] $\mathrm{N}$ Amil, $\mathrm{M} \mathrm{T}$ Latif, $\mathrm{M} \mathrm{F}$ Khan, "Characterization and Source Apportionment of Fine Particulate Matter during 2011 Haze Episode in UKM Bangi, Malaysia, From Sources to Solution". Springer Singapore, pp.363-367, 2014.

[2] D V Bates, R Sizto, "Air pollution and hospital admissions in Southern Ontario: the acid summer haze effect", Environmental research, vol.43, no.2, pp. 317-331, Feb 1987.

[3] H Fromme, S Dietrich, D Twardella, et al. "Indoor air concentrations of particulate matter (PM10 and PM2. 5) in German schools", Air Pollution, vol.86, pp. 393-399, 2006.

[4] A.Ghulam, T Kusky, T. Teyip, Q Qin, "Subcanopy soil moisture modeling in n-dimensional spectral feature space", Photogrammetric Engineering and Remote Sensing, vol.77, no.2, pp.149-156, Feb. 2011. 
[5] K He, J Sun, X Tang, "Single image haze removal using dark channel prior. Pattern Analysis and Machine Intelligence", IEEE Transactions on, vol.33, no.12, pp.2341-2353, Dem. 2011.

[6] J Long, Z Shi, W Tang, et al. "Single Remote Sensing Image Dehazing". 2014.

[7] M B Meyer, Michael, J E Jiusto, G G Lala, "Measurements of Visual Range and Radiation-Fog(Haze) Microphysics", Journal of the Atmospheric Sciences, vol.37, no.3, pp. 622-629. Mar.1980.

[8] T Pachauri, V Singla, A Satsangi, et al. "Characterization of major pollution events (dust, haze, and two festival events) at Agra, Indi", Environmental Science and Pollution Research, vol.20, no.8, pp. 5737-5752, Aug. 2013.

[9] S S Park, S A Jung, B J Gong, et al. "Characteristics of PM 2.5 Haze Episodes Revealed by Highly Time-Resolved Measurements at an Air Pollution Monitoring Supersite in Korea". Aerosol and Air Quality Research, vol.13, no.3, pp. 957-976, Mar. 2013. [10] C A Pope, "Respiratory hospital admissions associated with PM10 pollution in Utah, Salt Lake, and Cache Valleys", Archives of Environmental Health: An International Journal, vol.46, no.2, pp.90-97, Feb.1991.

[11] M M Zou, L F Chen, J H Tao, et al. "Accuracy analysis of PPDF-based method to parameterize aerosol scattering effect.",
Science China: Earth Sciences, vol.43, no.12, pp. 2062-2071. 2013.

[12] Y Lv, Z Q Li, P F Yin, et al. "Joint use of ground- based LiDAR and sun-sky radiometer for observation of aerosol vertical distribution", Journal of Remote Sensing, vol.17, no.4, pp.1008-1020, April. 2013.

[13] S Hasheminassab, N Dahera, M M. Shaferb, et al. "Chemical characterization and source apportionment of indoor and outdoor fine particulate matter (PM2.5) in retirement communities of the Los Angeles Basin", Science of The Total Environment, Vol 490, no.15 pp.528-537, Aug 2014.

[14] D. Dominick, H Juahir, MT Latif, SM Zain, AZ Aris, "Spatial assessment of air quality patterns in Malaysia using multivariate analysis" Atmos Environ, vol.60, pp.172-181.2012.

[15] MD Keywood, GP Ayers, JL Gras, R Boers, $\mathrm{CP}$ Leong, "Haze in the Klang Valley of Malaysia", Atmos Chem Phys, vol. 3, pp.591-605, Jun 2003

[16] R Afroz, MN Hassan, NA Ibrahim, "Review of air pollution and health impacts in Malaysia",

Environ Res, vol. 92, no.2, pp.71-77, June 2003.

[17] III CA Pope, DW Dockery, " Health effects of fine particulate air pollution: lines that connect" Journal of the Air \& Waste Management Association, vol.56, no.6, pp.709-742, June 2006. 